\title{
The Communication System in Project Teams: Problems of Transfer of Knowledge and Information for the Management of IT Projects
}

\author{
Jerzy Kisielnicki \\ Faculty of Management, Warsaw University, Warsaw, Poland \\ jerzy@kisielnicki.edu.pl
}

\begin{abstract}
The papers analysis the problem of organizing project teams to create conditions conducive to the seamless flow of knowledge between project participants and thus strengthen the team's synergy. The main hypothesis is "The network communication system provides the most effective framework for the management of the information technology (IT) projects". A network communication system is a system where communication between all team members is direct and crossdivisional. In such a system, the key role of a leader is to build an effective communication framework in addition to developing mutual trust within the team. Theoretical analysis and research of twenty two IT projects concluded that network organizations have a significant advantage over hierarchical ones in the following areas: progress monitoring, cooperation and knowledge transfer, and problem resolution.
\end{abstract}

Keywords: IT management, ICT project management, project team, leadership, Knowledge Management

\section{Introduction}

Success and failure in information technology (IT) projects depend on many factors. Based on the analysis of literature as well as this author's research and experience, we can build a working hypothesis of a significant influence of the communication system on a final project outcome in the context of:

- Communication between the project team and the outside world (users, suppliers, other project teams, etc.)

- Communication within a project team.

In project management literature, communication occupies a significant position (Cadle \& Yeates, 2004; Lee-Kelley \& Sankey, 2008; Maylor, 2003; Schelle, Ottmann, \& Pfeiffer, 2006).

Material published as part of this publication, either on-line or in print, is copyrighted by the Informing Science Institute. Permission to make digital or paper copy of part or all of these works for personal or classroom use is granted without fee provided that the copies are not made or distributed for profit or commercial advantage AND that copies 1) bear this notice in full and 2) give the full citation on the first page. It is permissible to abstract these works so long as credit is given. To copy in all other cases or to republish or to post on a server or to redistribute to lists requires specific permission and payment of a fee. Contact Publisher@InformingScience.org to request redistribution permission.
However, most research projects are focused on the analysis of communication between the project team and the outside world, communication within the project team seems to take a second place. From the literature dealing with building effective project teams, research carried out by L. Mullins (2001) deserves closer look. Mullins researched the key contradiction within a project team; he discovered that project leaders 
demand from their team members the willingness to compromise and subordination while at the same time they promote individualism and willingness to foster creativity. On the other hand J. Chaffe (2001) concluded that most people, during their professional career, loose both their creativity and individualism and prefer to conform to the existing standards. This is the essential reason why some leaders prefer to build their teams from young people knowing that they lack of experience. By doing that, they realize that they increase the risk of not achieving their goals. Therefore the IT leaders need to combine these conflicting trends and build the project team to ensure the overall success of the project. J. Adair (1999) indicates three criteria that need to be taken into consideration when evaluating potential team members: competence, motivation, and personal traits. An interesting description of the communication system in project groups presented by some of the most well-known consultants for the analysis of process design D. Cleland and R. Gareis (2006). They describe how virtualization affects the success in the transfer of knowledge. Analysis of communication systems has been the subject of many papers on the 23 World Congress IPMA (International Project Management Association). There were analyzed the differences among other things, problems in communication between small and large project teams (Silvius, Schipper, \& Rorije, 2010). Small teams want to exchange knowledge between themselves. Large teams are isolated from other teams and communicate knowledge only within their team. Large impact on the communication system has the type of project. Most IT projects are projects innovative. In this type of project it is necessary to transfer knowledge. It is for these teams realizing IT projects, it is recommended the organization network (Kisielnicki \& Sroka, 2010).

The subject of this paper is to prove the hypothesis that the communication system within the team significantly influences its effectiveness. The key question that needs to be answered is: what conditions the project leader needs to create in order to maximize the positive and minimize the negative effects of teamwork?

At first glance this hypothesis might seem obvious, detailed analysis does not lead to decisive conclusions. While executing the project, teams could use different communication methods to both, define the project tasks, as well as evaluate results. The effectiveness of various communication methods can be very different therefore we want to prove the hypothesis that:

The network communication system provides the most effective framework for the management of the information technology projects

Network communication system is a system where communication between all team members is direct and cross divisional. In such system, the role of a project leader is not only to build the seamless flow of information between the team members but also to build trust between them. Simple network communication system is illustrated in Figure 1.

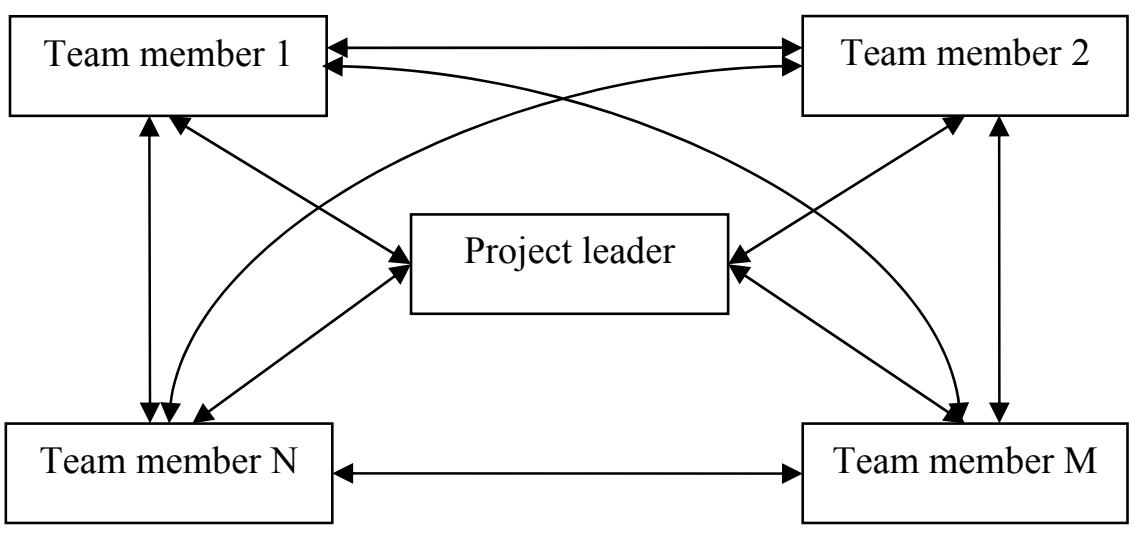

Figure 1. Simple network communication system 
During my professional career in IT I went through all steps of a corporate ladder, from a systems analyst to a senior project manager in charge of large software delivery projects. I researched the effectiveness of many IT projects but did not investigate large projects from other industries, for example, construction. Despite that, the results of my research can be adapted to any other industry, since the primary focus was on the internal project communication, which is generic rather than industry-specific.

My research was related to the application of the Transitive Memory Systems (TMS), conducted primarily by A. Hollingshead, D. Wegner, T. Guiliano, and P. Hertel. R. Moreland and L. Myaskovsky (2000) analyzed the TMS as a structure to deliver data, information, and knowledge, to the project teams. The research of 69 project teams indicated that team stability, team member familiarity, and interpersonal trust all have a positive impact on the TMS. Consequently, the TMS has a positive influence on team learning, speed-to-market, and a success of new products (Akgün 2004).

This paper is organized as follows:

- Section one - covers the analysis of communication systems and their elements.

- Section two - covers a brief description of two most common communication systems: the traditional, hierarchical system and the contemporary, network-based system; both systems can exist in different variations.

- Section three - describes the recommended version of the network communication system, its benefits and limitations.

\section{Research Description - Analysis of Communication Systems}

The analysis of communication systems was based on twenty IT projects carried out between 2000 and 2008. The Author actively participated in twelve of these projects; the information about the remaining ten projects was based on project documentation as well as interviews with project participants. The main difficulty in the research is the fact that all projects are unique (the ideal research would require an experiment where the same team would carry out the same projects at the same time with the only difference being the communication method). Therefore the conclusions of this research are based on estimates.

The majority of the projects included in the research targeted the business process improvement of the large organizations through the use of information technology. The project range was quite broad: implementation of IT in accounting for the major textile factory, improvement of the existing IT application in the insurance and pension institution, implementation of MRP II / ERP in a pharmaceutical company, application of IT in a municipality of a large municipality, strategic application of a new IT for a National Bank, application of IT to improve the management of a large top-security penitentiary, and application of IT for education (use of information technology program for senior executives) etc.

These projects represent a very diverse group of IT implementations; eighteen of these projects were business applications for various industries and four were for non-profit organizations. Success was defined based on schedule, cost, and scope; the project was considered successful if a variance at project completion for these three metrics was $10 \%$ or less. Despite the fact that fifteen of these projects were classified as success, during their implementation, the teams had to overcome significant problems.

The size of project teams in each of these projects was twenty people or more. The teams were cross-divisional; they included both IT personnel as well as industry specialists. The selection of 
such teams allowed the Author to research a group that both required at least a three-level communication and could not be managed by one person. In such a project team, level one consisted of system analysts designing a system, level two consisted of operational managers or team leaders, and level three was a project leader accountable for the entire project. To complement the standard communication channels (i.e., project leader to team leader to system analyst), the Author researched communication channels between project leader and systems analyst and between system analysts themselves.

The Author searched for answers to the following questions:

- How effective are main communication channels within a project team? Did the team members receive adequate information and knowledge from other team members?

- What project management methods would ensure a seamless information flow within a project team?

- What communication system is recommended for implementation of IT projects?

In the context of this research, effective communication is measured by earlier defined project success criteria.

The method of research is asymmetrical; the focus is on identification of causes of failure while a success is treated as a given. The methods of analysis are:

- Review of project initial documentation (preliminary analysis, business case, application specifications etc.) and project progress documentation (schedule, budget, delivered scope).

- Questionnaires for both project managers and project team members.

- Author's notes from the project meetings where the team discussed project issues, risks, and solutions.

The information from the project meetings was the key source for the analysis while project documentation and questionnaires provided the necessary background and were used for further result verification and diagnosis. Project documents and questionnaire results indicated there was a problem while the discussions were a source of recommended solutions. In most cases, the discussions were within the project team with participation of specialists from other project teams or from user groups. Each significant deviation from budget, schedule, scope was presented and discussed. Project documents and questionnaire results would then help verify if decisions made by the group were effective. One of the key questions from the questionnaire was: Would you like to work with the same team on the next project?

Occasionally, the Author used the experiment where he would pass specific information to one team member or a group, and measure the time it would take for this information to reach all project members. In such an experiment, the Author would send email and check when the email is read, monitor the usage of project database, and monitor the usage of Internet. The analysis also included the understanding and usefulness of the information, as perceived by the project team, in the context of project scope, schedule and budget. The results showed that there are two categories of the roadblocks:

- Communication roadblocks caused by external factors like delay in supply of required technology, project financial issues, incomplete documentation supplied by users, change in regulations, strategic organization changes with the organization being on the receiving end of the project, unplanned absence of a team member, etc. 
- Communication roadblocks caused by the internal factors like: insufficient communication, lack of knowledge and experience in carrying out the project, personal conflicts within the team, errors in project managements, etc.

While external factors listed above affect the project in general, internal factors were strongly related to the flow of information within the team.

The communication system within the team was evaluated using the following criteria:

- How significant was cost, schedule, and scope variance at project completion?

- How effective was risk management process?

- How effective was a conflict resolution process?

- Were team members willing to cooperate and share knowledge?

- Were the team members willing to work together on the next project?

Considering the scope of this paper, the Author presents only the most important facets of the research.

\section{Communication Systems and Their Elements}

The research includes two communication systems used by project teams:

- The network-based system presented in its simplified form in Figure 1. In reality, the network system is more complex, since besides the project leader there are also team leaders accountable for delivery of portions of the overall solution. Fourteen projects selected for this research followed such structure and used the network-based communication method. The diagram depicting communication channels in such structure is presented in Figure 4.

- The traditional, hierarchical communication system depicted in its basic form in Figure 2. Eight projects selected for this research used the hierarchical communication system.

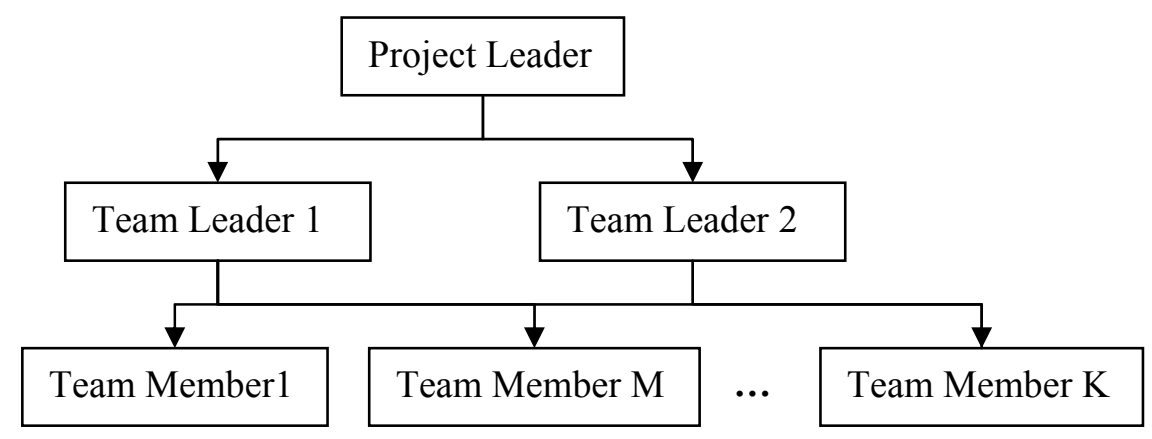

Figure. 2 The traditional three-level communication system

Regardless of the communication method, all projects were using various aspects of information technology to provide a business solution: Computer Aided System Engineering (CASE), databases, Internet and email, or on-line cooperation.

All communication systems within the project team include basic elements presented in Figure 3. 


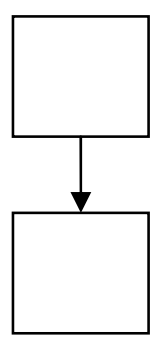

3a) hierarchical

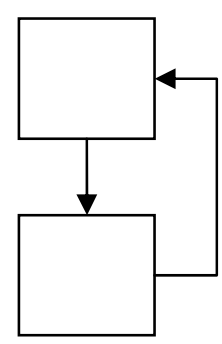

3b) hierarchical recursive

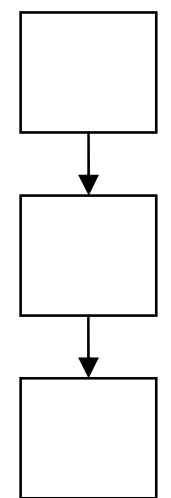

3c) hierarchical multilevel

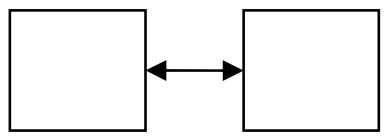

3d) parallel

Figure 3. Basic elements of communication systems.

Communication systems depicted in Figures 1 and 2 consist of "bricks" presented in Figure 3. The communication system is effective only if all individual bricks function properly. The information flow between these individual elements - regardless of the used technology - is deformed due to various disturbances caused by:

- Technology; hardware and software cannot transfer the contents and/or form of the information.

- Semantics; the recipient cannot read or interpret received information.

- Pragmatism; delivered information does not add anything new to the recipient's knowledge and consequently the effort to receive information was a waste.

Analysis of communication systems covered by this research proved that:

- Out of fourteen projects using network communication systems, eleven (80\%) were successful.

- Out of eight projects using traditional hierarchical communication systems, four $(50 \%)$ were successful. These four projects were MRPII/ERP-like package implementation projects.

As stated earlier, the communication system is not the only project success factor. However, the answers to the question quoted earlier, Would you like to work with the same team on the next project? were symptomatic.

- Amongst team members operating within the hierarchical communication system, between $60 \%$ and $70 \%$ of managers provided the positive answers while only $30 \%$ of system analysts provided a positive answer. 
- Amongst the team members operating within the network communication system, between $70 \%$ and $80 \%$ provided a positive answer and there were no difference between the management team and systems analysts.

In addition, the number and magnitude of project issues were much smaller in project using the network communication as compared to the projects using the hierarchical communication.

The results of research on the speed of information flow proved that in the network system information flow was 30\% faster than in the hierarchical systems. This research also proved the principles of management system design presented by M. Hammer in his business process reengineering method. According to M. Hammer (1995), it is critical to eliminate the "middle man" in order to improve the effectiveness of communication. Other scientists also confirmed these principles in their research (Kisielnicki, 2010 ).

Communication systems presented in Figures 2, 3a and 3c are the least desirable and not recommended as in these systems a team member only receives directives. Such situation in reality cannot and does not exist; there is always an exchange of information where the team member at least informs a project manager about a progress of the project tasks. However, as stated in works by L.Grochowski and J. Kisielnicki (2000), in the hierarchical relationship team members reluctantly inform the project leaders about the project progress even though they consider it their duty. It seems that the reason of such behavior is psychological; when asked why team members withhold information from project managers, the answers were ambiguous. Also discussions carried out within project teams did not bring about a conclusive answer (Awad \& Ghaziri, 2004). However, during one-on-one conversations, it became clear that team members perceive a project leader as a competitor; the typical answer was: If he is a project leader and receives higher salary, I will not advise him - it is up to him to make a decision.

G. Morgan (1986) in his work on different organization, writes that the hierarchy is a source of various conflicts between people. These conflicts are not about solving business problems; they are about people's position in organizational hierarchy. Based on observations, we can say that the situation is different when team members cooperate with each other and each individual's performance evaluation is driven by the evaluation of the final project outcome. In such environment cooperation becomes a necessity and knowledge transfer between team members is always significant. The leader's influence should focus on fostering, promoting, and demanding when necessary - knowledge transfer between the team members. F. Savatera (1998) writes: Greek preferred to solve issues with his equal rather than receive a solution from his Master; to make mistakes on his own behalf rather than to follow orders. The Author believes that people carrying out IT project these days are such contemporary Greeks.

There are two categories of IT projects:

- Package implementation projects (for example, implementation of MRP II/ ERP) where creativity is not as important as following standards and proven procedures. However, this approach is often criticized since in reality, the business processes and overall business environment change and package implementation projects do need to adopt the standard application to these changes.

- Projects that deliver new and unique applications where team members need to use creativity to a certain degree.

Therefore, (understanding the limitation pointed out above) the communication system presented in Figure $3 \mathrm{~b}$ is effective in package implementation projects where it is critical that the system delivery procedures are followed. For projects delivering new applications, communication pattern presented in Figure 3d is more appropriate. 
In a hierarchical communication system presented in Figure 2, the majority of elements is as presented in Figures 3a, 3b, and 3c. In a network communication system, the majority of elements are as presented in Figure 3d.

\section{The Network Communication System and Its Evolution; Comparative Analysis}

In reality, the network communication system depicted in Figure 1 is used for project teams consisting of five to seven people. For larger teams, this model takes on a more complex form presented in Figure 4. This diagram represents a modification of the network communication system presented by H. Mintzberg (1999).

The network communication system (presented on Figure 4) is therefore recommended for implementation of complex IT systems. This system has been proven in several IT implementations projects; it was well received by the team members, and, what is the most important, it was proven effective.

The network communication structure presented in Figure 4 has the following key characteristics:

1. Division of the project team into smaller teams happens dynamically during the project using two techniques: PERT combined with the Critical Path Method (CPM) as well as Management by Objectives (MBO). These techniques are supplemented with the analysis of skills and personality traits of the individual team members; (team building methods will be a subject of a separate paper).

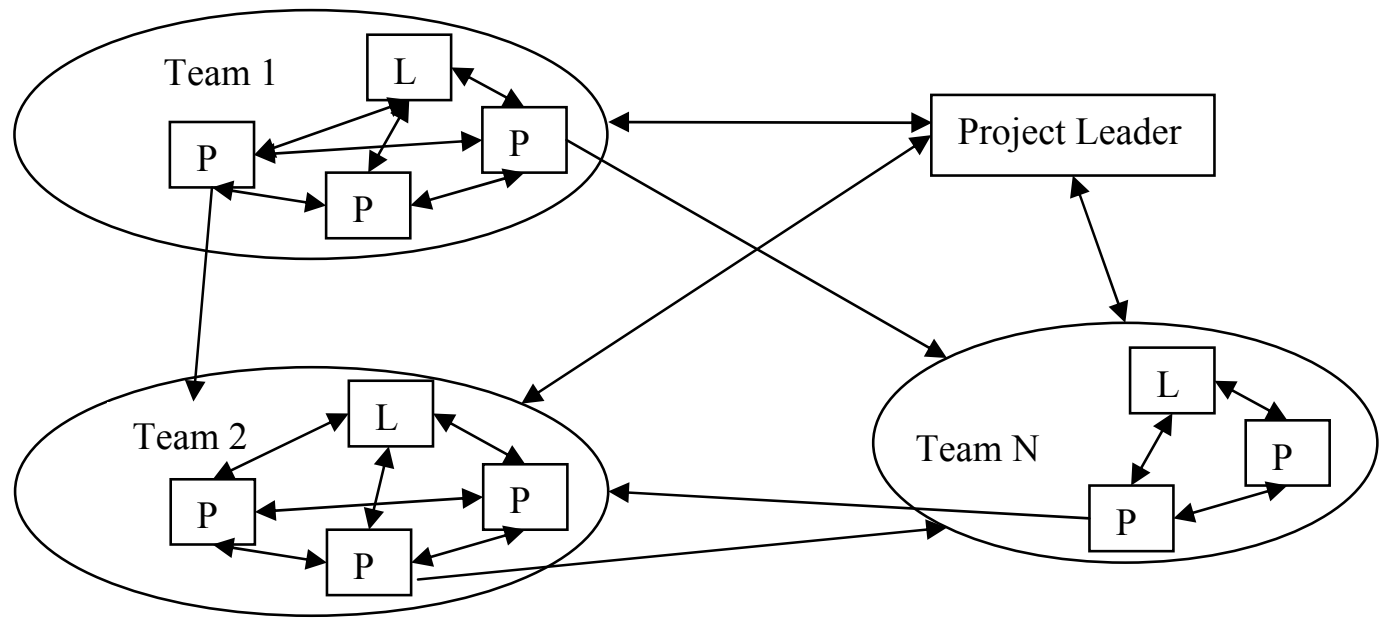

Legend:

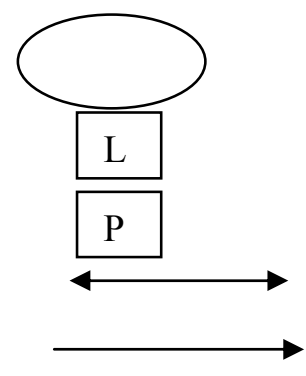

One of many project teams

Team Leader

Team Member

Information flow and organizational dependency

Team member from one team is temporarily reassigned to another team

Figure 4. Organizational structure and communication flow in a network-based project team. 
2. The network communication system is based on direct reports. The only person responsible for the entire project is a project leader. Team leaders have dual responsibility: they are both team leaders and team members (system analyst, business analyst, etc). During the project, after teams have completed their tasks, they were re-organized; the team leaders as well as team assignments would change.

Colloquium on Participant-Centered Learning organized by Harvard Business School in 2002 followed a very similar pattern; during discussions on various case studies, both team leaders and team members would periodically change. During the entire session the Author was a team leader only once and every week he was working in a different team. All participants accepted this method as obvious and natural. Also in the researched IT projects the team accepted the changes in team leaders. These changes were introduced and explained at the beginning of the project. Financial aspect of the team leader position was such that the position of a leader required additional effort as well as different skills, and was considered recognition. However, it did not trigger additional compensation. While changes in the team leader assignments worked well, reassignments to different teams were not. The reasons were two-fold:

- Schedule; different teams finished their deliverables in different times.

- Personal relationships created during the project between the individual team members. This was the significant element supporting a strong communication within the individual team.

3. Participation of team members from one team in achieving tasks of other team. For example, selected group of more experienced team members would spend $20 \%$ to $30 \%$ of their time assisting in completion tasks from other group. This arrangement builds the relationship between the project participants and facilitates the flow of information as well as knowledge transfer. Methods PERT/CPM as well as (MBO) help decide which teams should share resources in this manner.

\section{Conclusion}

Research on effectiveness of both communication systems indicates that the network communication systems are superior to the hierarchical system in the following aspects:

\section{Progress monitoring}

Possible deviations from scope, schedule and budget were communicated earlier in the network system than in a hierarchical system thus allowing for earlier intervention. This was due to the fact that all team members in the network system (TMS) felt responsible for the project success.

2. Cooperation and knowledge transfer.

There was a strong cooperation as well as knowledge and information transfer between team members; there were no artificial barriers (i.e., manager against worker). Each team member was or could be a team leader depending on the need and situation.

\section{Problem solving}

There were fewer conflicts within the network structure. The problems that did occur were less intense and they were resolved faster than within the hierarchical structure.

The communication system (TMS) in a network structure, to be effective, requires that several conditions be met. The most important one is the competence of individual team members and their willingness to cooperate. This system is difficult for so called individualists as well as people preparing for a project management career path. In the recommended system, career path is 
leads towards professional development but does not provide a stepping stones from a system analyst position to a project leader position. It is also a system difficult for the project manager whose responsibility stretches from hiring and organizing the team members, as well as creating atmosphere conducive to open communication and cooperation. Comparing to the hierarchical system, project leaders of network organizations need to delegate more of their duties to the teams while they retain full accountability of the overall project success. For this very reason many project leaders prefer the hierarchical system as easier to execute (it allows them to rely on formal authority) and to enforce the timeliness of delivery even though they fully understand its limitations.

These conclusions however, still do not provide a decisive answer the following questions:

- Which of these two systems is effective for all IT projects?

- What is the efficiency of replacing the hierarchical system with a network system?

Each business process needs to be both effective and efficient and an information system delivery process is no exception. There are many contributing factors that influence both its efficiency and effectiveness. Therefore in conclusion the Author would like to point out that the communication system, however critical to project success, is only one of these factors. Additional influence comes from the team makeup and as well as motivation techniques. The hiring and team building has been briefly discussed already. The effective motivation system, while critical to the overall communication strategy within the project team, is a separate topic. The effective motivation system also depends on the organizational culture, overall state of economy (the job market in particular) as well as the country itself; different motivation systems will be effective in India, Great Britain, Poland, or the United States. The communication system remains a key component in building effective teams since it is independent from team make-up and utilized motivation techniques.

\section{References}

Adaira, J. (1999). Decision making and problem solving (Management shapers). Chartered Institute of Personnel and Development (CIPD).

Akgün, A. E., Keskin, H., Byrne, J., \& Imamoglu, S.Z. (2005). Knowledge networks in new product development projects: A transitive memory perspective. Information and Management, 42(8), 1105-1120.

Awad, E. M., \& Ghaziri, H. M. (2004). Knowledge management. New Jersey: Pearson.

Cadle, J., \& Yeates, D. (2004). Project management for information systems. Harlow, England: Prentice Hall.

Cleland, D., \& Gareis, R. (2006). Global project management handbook. New York: McGraw-Hill.

Chaffee, J. (2000). The thinker's way: 8 Steps to a richer life. Little Brown Co.

Grochowski, L., \& Kisielnicki, J. (2000). Reengineering in upgrading of public administration: Modelling and design. International Journal of Services Technology and Management, 1(4), 331.

Hammer, M. (1995). The reengineering revolution. HarperBusiness.

Hollingshead, A. (1998). Retrieval processes in transactive memory systems. Journal of Personality and Social Psychology, 74, 659-671.

Kisielnicki, J. (2002). IT in improvement of public administration. In M. Khosrow-Pour (Ed.), Cases on information technology. Hershey, PA, London: Idea Group.

Kisielnicki J. (2010). Management. Warszawa: PWE (in Polish).

Kisielnicki, J., \& Sroka, S., (2010). Theory and practice of innovative, challenges \& opportunities. 24th IPMA World Congress, Istanbul. 
Lee-Kelley, L., \& Sankey, T., (2008). Global virtual teams for value creation and project success: A case study. International Journal of Project Management, 26(1), 51-62.

Maylor, H. (2003). Project management. Harlow, England: Prentice Hall.

Mintzberg, H., \& Van der Heyden, L. (1999). Organigraphs: Drawing how companies really work. Harvard Business Review, Sept.-Oct., 87.

Morgan, G. (1986). Image of organization. Newbury Park - London: SAGE Pub.

Moreland, R. L., \& Myaskovsky, L. (2000). Exploring the performance benefits of group training: Transitive memory or improved communication? Organizational Behavior and Human Decision Processes $82,117-133$

Mullins, L. (1993). Management and organizational behavior. London: Pitman Publishing.

Savatera, F. (1998). Polityka para Amador. Editorial Ariel S.A., Barcelona.

Schelle, H., Ottmann, R., \& Pfeiffer, A. (2006). Project manager. Nuremberg: GPM.

Silvius, G., Schipper, R., \& Rorije, H. (2010). Creating sustainable change: A new paradigm in project management. Challenges \& Opportunities, 24th IPMA World Congress, Istanbul

Wegner, D. M. (1995). A computer network model of human transitive memory, Social Cognition, 13, 319339.

Wegner, D. M., Guiliano, T., \& Hertel, P.T. (1985). Cognitive interdependence in close relationships. In W. J. Ickes (Ed.), Compatible and incompatible relationships (pp. 253-276). New York: SpringerVerlag.

\section{Biography}

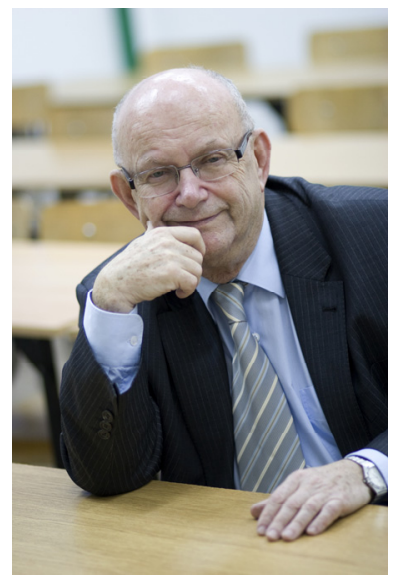

Jerzy Kisielnicki received a Ph.D. at the Warsaw School of Economics (S.G.P.i.S.) in 1969, and received a doctorate in 1969, and received a doctorate of Habilation in 1976 at the Warsaw University, Poland. He became a professor of economics in 1986, and he's been a full professor since 1992. Dr. Kisielnicki has been the head of the Department of Information Systems in Management and Faculty of Management at Warsaw University since 1972, and has been the head of the Department of Management at Marketing at the School of Economics (WSHiP) since 1995.

His interests are organization and management, systems analysis, management information systems, e-learning, process innovation (reengineering), strategic management, and transition systems organisation and management in market economy. He is a member Institute for Operations Research and the Management Science TIMS-ORSA. Dr. Kisielnicki is a member of the Board of Organization and Management in Polish Academy of Science and is the head of the Scientific Council of Polish Society of Systems Information. He has had about 220 publications. 